Pacific Journal of Mathematics

ON BLASCHKE PRODUCTS OF RESTRICTED GROWTH 


\title{
ON BLASCHKE PRODUCTS OF RESTRICTED GROWTH
}

\author{
C. N. LINDEN
}

\begin{abstract}
Let $\mathscr{F}$ denote the class of Blaschke products $B\left(z,\left\{z_{n}\right\}\right)$ such that

$$
\int_{0}^{2 \pi}\left(\log \left|B\left(r e^{i \theta},\left\{z_{n}\right\}\right)\right|\right)^{2} d \theta
$$

is bounded for $0<r<1$. The distributions of the zeros of Blaschke products in $\mathscr{F}$ are examined, and extensions are made to earlier results of MacLane and Rubel.
\end{abstract}

1. Let $\left\{z_{n}\right\}$ be a nonempty sequence of nonzero complex numbers in $D(0,1)=\{z:|z|<1\}$. Then $\left\{z_{n}\right\}$ is a Blaschke sequence if and only if

$$
\sum_{n}\left(1-\left|z_{n}\right|\right)<\infty
$$

If (1.1) holds then the Blaschke product

$$
B\left(z,\left\{z_{n}\right\}\right)=\prod_{n} \frac{\bar{z}_{n}}{\left|z_{n}\right|}\left(\frac{z_{n}-z}{1-z \bar{z}_{n}}\right)
$$

represents a function $B\left(z,\left\{z_{n}\right\}\right)$ regular in $D(0,1)$. It is well-known that $\left|B\left(z,\left\{z_{n}\right\}\right)\right|<1$ when $z \in D(0,1)$, and that

$$
\lim _{r \rightarrow 1-0} B\left(r e^{i \theta},\left\{z_{n}\right\}\right)
$$

exists and has modulus 1 for almost every $\theta$ in $[0,2 \pi]$.

Let

$$
I\left(r,\left\{z_{n}\right\}\right)=\frac{1}{2 \pi} \int_{0}^{2 \pi}\left(\log \left|B\left(r e^{i \theta},\left\{z_{n}\right\}\right)\right|\right)^{2} d \theta .
$$

MacLane and Rubel [3] have considered the class $\mathscr{F}$ of Blaschke products for which $I\left(r,\left\{z_{n}\right\}\right)$ is bounded on $[0,1)$. They have shown that a necessary and sufficient condition for $B\left(z,\left\{z_{n}\right\}\right)$ to belong to $\mathscr{J}$ is that $J\left(r,\left\{z_{n}\right\}\right)$ is bounded on $[0,1)$, where

$$
J\left(r,\left\{z_{n}\right\}\right)=\sum_{k=1}^{\infty} k^{-2}\left|\left(r^{k}-r^{-k}\right) \sum_{\left|z_{n}\right| \leqq r} \bar{z}_{n}^{k}+r^{k} \sum_{\left|z_{n}\right|>r}\left(\bar{z}_{n}^{k}-z_{n}^{-k}\right)\right|^{2} .
$$

In fact, the work of Rubel [4] shows that

$$
J\left(r,\left\{z_{n}\right\}\right)=2 I\left(r,\left\{z_{n}\right\}\right)-2\left\{N\left(r,\left\{z_{n}\right\}\right) \log r+\log \prod_{\left|z_{n}\right|>r}\left|z_{n}\right|\right\}^{2},
$$

where $N\left(r,\left\{z_{n}\right\}\right)$ denotes the number of elements in the sequence $\left\{z_{n}\right\}$ 
that belong to $\{z:|z| \leqq r\}$.

Observing the difficulty in interpreting the condition that $J\left(r,\left\{z_{n}\right\}\right)$ is bounded on $[0,1)$, MacLane and Rubel sought to relate this condition to the distribution of the elements of the sequence $\left\{z_{n}\right\}$ in $D(0,1)$. They proved the following results.

I. If

$$
N\left(r,\left\{z_{n}\right\}\right)=O\left((1-r)^{-1 / 2}\right) \text { as } r \rightarrow 1-0
$$

then $B\left(z,\left\{z_{n}\right\}\right) \in \mathscr{F}$.

II. If the elements of the sequence $\left\{z_{n}\right\}$ lie on a finite number of radii of $D(0,1)$ then $B\left(z,\left\{z_{n}\right\}\right) \in \mathscr{J}$ only if (1.6) holds.

III. There exists a Blaschke sequence $\left\{z_{n}\right\}$ such that

while

$$
\lim _{r \rightarrow 1-0} I\left(r,\left\{z_{n}\right\}\right)=0 \text {, }
$$

$$
\lim _{r \rightarrow 1-0} N\left(r,\left\{z_{n}\right\}\right)(1-r)^{\lambda}=\infty
$$

for every $\lambda$ in $[0,1)$.

The aim of this paper is to obtain some further global properties of the distributions of those sequences $\left\{z_{n}\right\}$ for which $I\left(r,\left\{z_{n}\right\}\right)$ is bounded on $[0,1)$. Essentially we extend the result II above, but before stating our intentions precisely we need to establish some suitable notation. If $\theta$ is real, $\varphi \geqq 0$, and $0 \leqq r<1$ let

$$
A(r, \theta, \varphi)=\left\{\begin{array}{lc}
\left\{z:|\theta-\arg z| \leqq 2 \varphi, r<|z| \leqq \frac{1}{2}(1+r)\right\}, \\
\left\{z: r<|z| \leqq \frac{1}{2}(1+r)\right\}, & 0 \leqq \varphi<\frac{1}{2} \pi,
\end{array}\right.
$$

and let $\nu\left(r, \theta, \varphi,\left\{z_{n}\right\}\right)$ denote the number of elements of the sequence $\left\{z_{n}\right\}$ that are in $A(r, \theta, \varphi)$. Depending on the value $\varphi, A(r, \theta, \varphi)$ is either an annulus or a subset of an annulus that is bounded by parts of two radii of the circles which bound the annulus. The significance of such regions has arisen elsewhere [2] in the theory of regular functions. We now state the following theorem.

THEOREM 1. Let $\left\{z_{n}\right\}$ be a Blaschke sequence such that

$$
I\left(r,\left\{z_{n}\right\}\right)<M<\infty, \quad 0<r<1 .
$$

Then there is an absolute constant $C$ such that

$$
\nu\left(r, \theta, \kappa(1-r)^{r},\left\{z_{n}\right\}\right)<\frac{C M^{1 / 2}\left(1+\kappa^{1 / 2}\right)}{r(1-r)^{1 / 2}}, \quad 0<r<1,0 \leqq \theta<2 \pi
$$


when $\gamma \geqq 1$, and

$$
\nu\left(r, \theta, \kappa(1-r)^{\gamma},\left\{z_{n}\right\}\right)<\frac{C M^{1 / 2}\left(1+\kappa^{1 / 2}\right)}{r(1-r)^{1-1 / 2 \gamma}}, 0<r<1,0 \leqq \theta<2 \pi
$$

when $0 \leqq \gamma<1$.

The result II of MacLane and Rubel shows that the order of magnitude of the right-hand side of (1.9) is best possible for small values of $1-r$. That the order of magnitude of the right-hand side of (1.10) is also best possible when $0<\gamma<1$ is proved as a theorem which we state as follows.

THEOREM 2. Let $0<\gamma<1$. Then there is a Blaschke product $B\left(z,\left\{z_{n}\right\}\right)$ in $\mathscr{J}$ such that

$$
\nu\left(r, 0,(1-r)^{\gamma},\left\{z_{n}\right\}\right) \sim\left(2^{1-1 / 2 \gamma}-1\right)(1-r)^{-1+1 / 2 \gamma}
$$

as $r \rightarrow 1-0$.

In $\S 4$ we will look more closely at the implications of Theorem 1 and Theorem 2. However, we will first turn our attention to the proofs of these two theorems.

2. The proof of Theorem 1. In proving Theorem 1, we make use of the following lemma.

LEmmA 1. Let $\left\{z_{n}\right\}$ satisfy the hypothesis of Theorem 1. Then there is an absolute constant $C$ such that

$$
\nu\left(r, \theta, \varphi,\left\{z_{n}\right\}\right)<\frac{C M^{1 / 2}\left((1-r)^{1 / 2}+\varphi^{1 / 2}\right)}{r(1-r)}
$$

for $0<r<1,0 \leqq \theta<2 \pi, \varphi \geqq 0$.

Theorem 1 is deduced immediately by substituting $\varphi=\kappa(1-r)^{r}$ in the lemma, and considering separately the cases where $\gamma \in[0,1)$ and $y \in[1, \infty)$.

We must now prove Lemma 1 . In doing so we suppose without loss of generality that $\theta=0$ and $\sin \varphi<1 / 8$. We will also suppose that $\varphi \neq 0$ since the amendments to the proof that are necessary to cover the case where $\varphi=0$ are obvious.

Every term in the Blaschke product (1.2) has modulus less than 1 when $0<|z|<1$ and $0<\left|z_{n}\right|<1$. Hence, if $\left\{\alpha_{n}\right\}$ is a subsequence of $\left\{z_{n}\right\}$, we have

$$
I\left(R,\left\{\alpha_{n}\right\}\right)<I\left(R,\left\{z_{n}\right\}\right)<M, \quad 0<R<1,
$$

and therefore, by (1.5), 


$$
J\left(R,\left\{\alpha_{n}\right\}\right)<2 M, \quad 0<R<1 .
$$

Let $\left\{\alpha_{n}\right\}$ be that (finite) subsequence of $\left\{z_{n}\right\}$ which is contained in $A(r, 0, \varphi)$, and let $R=\frac{1}{2}(1+r)$. Then, since $\left|\alpha_{n}\right| \leqq R$ for all relevant values of $n,(2.1)$ and the definition of $J\left(R,\left\{\alpha_{n}\right\}\right)$ yield

$$
\sum_{k=1}^{\infty} \frac{1}{k^{2}}\left(R^{-k}-R^{k}\right)^{2}\left|\sum_{n} \bar{\alpha}_{n}^{k}\right|^{2}<2 M .
$$

We now set $L=1+[1 / 8 \varphi]$, noting that if $1 \leqq k \leqq L$ then

$$
\left|\arg \bar{\alpha}_{n}^{k}\right| \leqq \pi L\left|\sin \frac{1}{2}\left(\arg \alpha_{n}\right)\right| \leqq \pi\left(1+\frac{1}{8 \phi}\right) \sin \varphi<\frac{\pi}{4} .
$$

Hence, we have

$$
\left|\sum_{n} \bar{\alpha}_{n}^{k}\right|^{2} \geqq\left(\sum_{n} \mathscr{R} \bar{\alpha}_{n}^{k}\right)^{2}>\frac{1}{2} r^{2 k} \nu\left(r, 0, \varphi,\left\{z_{n}\right\}\right)^{2},
$$

and it follows from (2.2) that

$$
\nu\left(r, 0, \varphi,\left\{z_{n}\right\}\right)^{2} \sum_{k=1}^{L} \frac{r^{2 k}}{k^{2}}\left(R^{-k}-R^{k}\right)^{2}<4 M .
$$

In dealing with (2.3) we note that an application of the meanvalue theorem shows that

$$
R^{-k}-R^{k}=R^{-k}\left(1-R^{2 k}\right)>2 k R^{k-1}(1-R), \quad 0<R<1,
$$

so that

$$
\begin{aligned}
\sum_{k=1}^{L} \frac{r^{2 k}}{k^{2}}\left(R^{-k}-R^{k}\right)^{2} & >4(1-R)^{2} \sum_{k=1}^{L} r^{2 k} R^{2 k-2} \\
& =4 r^{2}(1-R)^{2}\left(\frac{1-r^{2 L} R^{2 L}}{1-r^{2} R^{2}}\right) \\
& >\frac{r^{2}}{3}(1-r)\left(1-r^{2 L}\right),
\end{aligned}
$$

since $R=\frac{1}{2}(1+r)$ and $0<r<1$. Therefore (2.3) yields

$$
\nu\left(r, 0, \varphi,\left\{z_{n}\right\}\right)^{2}<\frac{12 M}{r^{2}(1-r)\left(1-r^{2 L}\right)} \quad 0<r_{:}<1 .
$$

However, by elementary properties of the exponential function, we have

$$
\begin{aligned}
1-r^{2 L} & >1-e^{-2 L(1-r)} \\
& >1-e^{-(1-r) / 4 \varphi} \\
& >\frac{1-r}{4 \varphi+1-r},
\end{aligned}
$$


so that (2.4) implies that

$$
\nu\left(r, 0, \varphi,\left\{z_{n}\right\}\right)^{2}<\frac{48 M(\sqrt{\varphi}+\sqrt{(1-r)})^{2}}{r^{2}(1-r)^{2}},
$$

thus completing the proof of Lemma 1.

\section{The Proof of Theorem 2 .}

3.1. Preliminaries. In proving Theorem 2 we consider a Blaschke sequence $\left\{z_{n}\right\}$ defined as follows. Let $0<\gamma<1$, and let $\beta$ satisfy the inequality

$$
\frac{2}{2-\gamma} \leqq \beta
$$

Then we set

$$
z_{n}=\left(1-\frac{1}{n^{\beta}}\right) e^{i n-\beta \gamma}, \quad n=2,3, \cdots
$$

We shall, in fact, put $\beta=\left(1-\frac{1}{2} \gamma\right)^{-1}$ for the proof of Theorem 2 itself. However, it is no more difficult to prove our preliminary results in the general case specified by (3.1) than in the particular case, so we consider the general case as this leads to Corollary 4 which we mention later.

By (3.1) we have $\beta>1$ so that $\left\{z_{n}\right\}$ is a Blaschke sequence. Further, if $0<r<1$ and

$$
r<\left|z_{n}\right| \leqq \frac{1}{2}(1+r),
$$

then

$$
\begin{aligned}
& (1-r)^{-1 / \beta}<n \leqq\left(\frac{1}{2}(1-r)\right)^{-1 / \beta} \\
& \left(\frac{1}{2}(1-r)\right)^{\gamma} \leqq \arg z_{n}<(1-r)^{\gamma}
\end{aligned}
$$

Hence

$$
\nu\left(r, 0,(1-r)^{r},\left\{z_{n}\right\}\right) \sim\left(2^{1 / \beta}-1\right)(1-r)^{-1 / \beta}
$$

as $r \rightarrow 1-0$, which is (1.11) when $\beta=\left(1-\frac{1}{2} \gamma\right)^{-1}$.

It remains to show that $B\left(z,\left\{z_{n}\right\}\right) \in \mathscr{F}$, and to this end we show that

$$
I\left(r,\left\{z_{n}\right\}\right)=O\left((1-r)^{(2 \beta-2-\beta \gamma) / \beta}+(1-r)^{(2 \beta-2-\beta \gamma) / \beta \gamma}+(1-r)^{\gamma / 2}\right)
$$

as $r \rightarrow 1-0$. Before verifying (3.4) we must find suitable bounds to the moduli of the factors of the Blaschke product $B\left(z,\left\{z_{n}\right\}\right)$ subject to (3.2). The following elementary results will be applied at various stages during this investigation. 
Lemma 2. If $b$ is real then

$$
\sum_{n=1}^{N} n^{-b}=O\left(N^{1-b}+\log N\right) \text { as } N \rightarrow \infty,
$$

and if $b>1$ then

$$
\sum_{n=N}^{\infty}=O\left(N^{1-b}\right) \text { as } N \rightarrow \infty
$$

Lemma 3. If $a>0$ and $b>0$ then

$$
\sum_{n=1}^{N} \frac{1}{a^{2}+n^{2} b^{2}}<\frac{4 N}{(a+b)(a+N b)}, \quad N=1,2,3, \cdots,
$$

and

$$
\sum_{n=1}^{\infty} \frac{1}{a^{2}+n^{2} b^{2}}<\frac{4}{(a+b) b}<\frac{4}{a b} .
$$

Lemma 4. If $a_{1}, a_{2}, \cdots, a_{N}$ are real numbers then

$$
\left(\sum_{n=1}^{N} a_{n}\right)^{2} \leqq N \sum_{n=1}^{N} a_{n}^{2}
$$

LemMA 5. If $\theta$ and $1-r$ are nonnegative and not both zero, and if $b$ is real then

$$
2^{-|b-1|} \leqq \frac{(\theta+1-r)^{b}}{\theta^{b}+(1-r)^{b}} \leqq 2^{|b-1|}
$$

3.2. Estimates for the Blaschke factors. In the remainder of this section we shall let $K$ denote a positive number, independent of $r, \theta$, and $n$. The value to be ascribed to $K$ will vary from time to time, but it should be noted that at each appearance there will be some way of determining $K$ in terms of $\beta$ and $\gamma$. We suppose also, without loss of generality, that $\frac{1}{2}<r<1$, noting that $\frac{1}{2}<\left|z_{n}\right|<1$ by hypothesis.

Let $z=r e^{i \theta}$ and $z_{n}=r_{n} e^{i \theta_{n}}$. Then

$$
\frac{1}{\left|B\left(r e^{i \theta},\left\{z_{n}\right\}\right)\right|^{2}}=\prod_{n=2}^{\infty}\left\{1+\frac{\left(1-r^{2}\right)\left(1-r_{n}^{2}\right)}{Q\left(r, r_{n}, \theta, \alpha_{n}\right)}\right\}
$$

where

$$
Q\left(r, r_{n}, \theta, \alpha_{n}\right)=\left(r-r_{n}\right)^{2}+4 r r_{n} \sin ^{2} \frac{1}{2}\left(\theta-\alpha_{n}\right) .
$$

Now $\alpha_{n}=n^{-\beta r}$ so that $\alpha_{n} \in(0, \pi)$. For the remainder of this subsection we shall assume that $\theta \in[0, \pi]$. Then 


$$
Q\left(r, r_{n}, \theta, \alpha_{n}\right) \geqq\left(r-r_{n}\right)^{2}+\left(\frac{\theta-\alpha_{n}}{\pi}\right)^{2}
$$

For given values of $\theta$ and $r$ let

$$
F_{\theta}=\left[\frac{1}{2} \theta^{-1 / \beta r}, 2 \theta^{-1 / \beta r}\right], G_{r}=\left[\frac{1}{2}(1-r)^{-1 / \beta}, 2(1-r)^{-1 / \beta}\right] .
$$

We consider successively the cases in which

$$
F_{\theta} \cap G_{r}=\varnothing \text { and } F_{\theta} \cap G_{r} \neq \varnothing \text {. }
$$

Subsequently we shall make use of the inequality

$$
\left|\theta-\alpha_{n}\right|=\left|\frac{\theta n^{\beta \gamma}-1}{\theta n^{\beta \gamma}+1}\right|\left(\theta+n^{-\beta \gamma}\right)>\left(\frac{2^{\beta \gamma}-1}{2^{\beta \gamma}+1}\right)\left(\theta+n^{-\beta \gamma}\right), \quad n \notin F_{\theta},
$$

and the similarly obtained inequality

$$
\left|r-r_{n}\right|>\left(\frac{2^{\beta}-1}{2^{\beta}+1}\right)\left(1-r+n^{-\beta}\right), \quad n \notin G_{r} .
$$

Let $\pi_{1}(z)$ denote the product of those terms in $B\left(z,\left\{z_{n}\right\}\right)$ for which $n \notin F_{\theta} \cup G_{r}$. Then using (3.7) and (3.8) we have, for such values of $n$,

$$
Q\left(r, r_{n}, \theta, \alpha_{n}\right)>K\left\{(1-r)^{2}+\theta^{2}+n^{-2 \beta \gamma}+n^{-2 \beta}\right\} .
$$

Putting $N=\max \left(2,\left[(1-r+\theta)^{-1 / \beta r}\right]\right)$, where $[x]$ denotes the integral part of $x$, we apply Lemma 5 to (3.9), and obtain from (3.5) and (3.6) the inequalities

$$
\begin{aligned}
\log \frac{1}{\left|\pi_{1}\left(r e^{i \theta}\right)\right|} & <\sum_{n=2}^{\infty} \frac{K(1-r) n^{-\beta}}{N^{-2 \beta \gamma}+n^{-2 \beta \gamma}} \\
& <K(1-r)\left\{\sum_{n=2}^{N} n^{2 \beta \gamma-\beta}+N^{2 \beta \gamma} \sum_{n=N+1}^{\infty} n^{-\beta}\right\} .
\end{aligned}
$$

Thus Lemma 2 yields

$$
\log \frac{1}{\left|\pi_{1}\left(r e^{i \theta}\right)\right|}<K(1-r)\left(N^{2 \beta \gamma-\beta+1}+\log N\right) .
$$

We suppose next that $F_{\theta} \cap G_{r}=\varnothing$. Then if $n \in F_{\theta}$ we have $n \notin G_{r}$. Hence, it follows from (3.6) and (3.7) that

$$
Q\left(r, r_{n}, \theta, \alpha_{n}\right)>K\left\{(1-r)^{2}+n^{-2 \beta}+\left(n-\theta^{-1 / \beta r}\right)^{2} \theta^{2+2 / \beta r}\right\}
$$

since, by the mean-value theorem,

$$
\left(n^{-\beta \gamma}-\theta\right)=\beta \gamma\left(\theta^{-1 / \beta \gamma}-n\right) \xi^{-\beta \gamma-1},
$$

where $\xi$ lies between $n$ and $\theta^{-1 / \beta r}$. Let $\pi_{2}(z)$ denote the product of 
those terms in $B\left(z,\left\{z_{n}\right\}\right)$ for which $n \in F_{\theta}$ when $F_{\theta} \cap G_{r}=\varnothing$. Then

$$
\log \frac{1}{\left|\pi_{2}\left(r e^{i \theta}\right)\right|}<\sum_{n \in F_{\theta}} \frac{K(1-r) \theta^{1 / \gamma}}{Q\left(r, r_{n}, \theta, \alpha_{n}\right)} .
$$

But if $\lambda=\left[2 \theta^{-1 / \beta r}\right]$ the number of integers $n$ in $F_{\theta}$ does not exceed $\lambda$. Hence

$$
\begin{aligned}
\log \frac{1}{\left|\pi_{2}\left(r e^{i \theta}\right)\right|} & <\sum_{k=0}^{\lambda} \frac{K(1-r) \theta^{1 / \gamma}}{(1-r)^{2}+\theta^{2 / \gamma}+k^{2} \theta^{2+2 / \beta \gamma}} \\
& <\frac{K(1-r) \theta^{(\beta-1) / \beta r}}{\left(1-r+\theta^{1 / \gamma}\right)(1-r+\theta)}+\frac{K(1-r) \theta^{1 / \gamma}}{\left(1-r+\theta^{1 / \gamma}\right)^{2}}
\end{aligned}
$$

by Lemma 3 and Lemma 5 .

We now put $\mu=\left[2(1-r)^{-1 / \beta}\right]$. Then, if $\pi_{3}(z)$ denotes the product of those terms in $B\left(z,\left\{z_{n}\right\}\right)$ for which $n \in G_{r}$ in the case where $F_{\theta} \cap G_{r}=\varnothing$, we can make estimates similar to those for $\pi_{2}(z)$ to obtain

$$
\begin{aligned}
\log \frac{1}{\left|\pi_{3}\left(r e^{i \theta}\right)\right|} & <\sum_{k=0}^{\mu} \frac{K(1-r)^{2}}{(1-r)^{2 \gamma}+\theta^{2}+k^{2}(1-r)^{2+2 / \beta}} \\
& <\frac{K(1-r)^{2}}{\left((1-r)^{2 \gamma}+\theta^{2}\right)}\left\{1+\frac{(1-r)^{\gamma}+\theta}{(1-r)^{1+1 / \beta}}\right\} \\
& <\frac{K(1-r)^{1-1 / \beta}}{(1-r)^{r}+\theta} .
\end{aligned}
$$

Finally, let us suppose that $F_{\theta} \cap G_{r} \neq \varnothing$. Then

$$
4^{-\beta}(1-r) \leqq \theta^{1 / r} \leqq 4^{\beta}(1-r) \text {, }
$$

and if $n \in F_{0} \cup G_{r}$ then

$$
1 / 8(1-r)^{-1 / \beta} \leqq n \leqq 8(1-r)^{-1 / \beta} .
$$

Let $N(=N(\theta)$ ) denote the integer $N$ for which

$$
N \leqq \theta^{-1 / \beta r}<N+1
$$

If $n \in F_{\theta} \cup G_{r}$ then we can apply (3.11) and (3.14) to obtain

$$
\left|\theta-\alpha_{n}\right| \geqq K\left|\theta^{-1 / \beta \gamma}-n\right| \theta^{1+1 / \beta r} \geqq K\left|\theta^{-1 / \beta \gamma}-n\right|(1-r)^{\gamma+1 / \beta} .
$$

Now let $H_{\theta}=\{N-1, N, N+1, N+2\}$, and let $\pi_{4}(z)$ denote the product of those factors of $B\left(z,\left\{z_{n}\right\}\right)$ for which $n \in\left(F_{\theta} \cup G_{r}\right) \backslash H_{\theta}$ when $F_{\theta} \cap G_{r} \neq \varnothing$ : if $F_{\theta} \cap G_{r}=\varnothing$ we define $\pi_{4}(z)=1$ when $z \in D(0,1)$. Then, putting $\tau=\left[8(1-r)^{-1 / \beta}\right]$, and using (3.5), (3.6), and (3.15), we obtain

$$
\begin{aligned}
\frac{1}{\left|\pi_{4}\left(r e^{i \theta}\right)\right|} & \leqq \prod_{k=1}^{\tau}\left\{1+\frac{K(1-r)^{2(\beta-\beta \gamma-1) / \beta}}{k^{2}}\right\} \\
& <\exp \left(K(1-r)^{1-\gamma-1 / \beta}\right)
\end{aligned}
$$


by application of the product formula for the function cosh. We now define $\pi_{5}(z)$ to be the product of those factors of $B\left(z,\left\{z_{n}\right\}\right)$ for which $n \in H_{\theta}$ when $F_{\theta} \cap G_{r} \neq \varnothing$. If $F_{\theta} \cap G_{r}=\varnothing$ we define $\pi_{5}(z)=1$ when $z \in D(0,1)$. Then

$$
\frac{1}{\left|\pi_{5}\left(r e^{i \theta}\right)\right|} \leqq \prod_{n=N-1}^{N+2}\left\{1+\frac{4(1-r)\left(1-r_{n}\right)}{\sin ^{2} \frac{1}{2}\left(\theta-\alpha_{n}\right)}\right\}
$$

3.3. Completion of the Proof of Theorem 2. According to the notation of $\S 3.2$ we write

$$
B\left(z,\left\{z_{n}\right\}\right)=\prod_{j=1}^{5} \pi_{j}(z),
$$

noting that the numbers of Blaschke factors appearing in the subproducts $\pi_{j}(z)$ depend on $z$, and that some of the products may contain no Blaschke factors for some values $z$.

We must now verify (3.4). To begin with we have

$$
\begin{aligned}
I\left(r,\left\{z_{n}\right\}\right) & <2 \int_{0}^{\pi}\left(\log \left|B\left(r e^{i \theta},\left\{z_{n}\right\}\right)\right|\right)^{2} d \theta \\
& <10 \sum_{j=1}^{5} \int_{0}^{\pi}\left(\log \left|\pi_{j}\left(r e^{i \theta}\right)\right|\right)^{2} d \theta
\end{aligned}
$$

by Lemma 4 . We write

$$
I_{j}(r)=\int_{0}^{\pi}\left(\log \left|\pi_{j}\left(r e^{i \theta}\right)\right|\right)^{2} d \theta, \quad j=1,2,3,4,5,
$$

and find bounds to each of these integrals by using the bounds to the factors obtain in $\S 3.2$.

First, we apply Lemma 5 to (3.10) to obtain

$$
\begin{aligned}
I_{1}(r)< & K \int_{0}^{\pi}(1-r)^{2}\left((1-r+\theta)^{2(\beta-1-2 \beta r) / \beta \gamma}\right. \\
& \left.+(\log (1-r+\theta))^{2}+(\log 2)^{2}\right) d \theta \\
< & K(1-r)^{2}\left\{1+(1-r)^{(2 \beta-2-3 \beta r) / \beta r}\right\} \\
& \left.=0\{1-r)^{(2 \beta-2-\beta \gamma) / \beta \gamma}+(1-r)^{2}\right\}
\end{aligned}
$$

as $r \rightarrow 1-0$.

Next we observe that (3.12) and Lemma 5 implies that

$$
I_{2}(r)<K\left(J_{2}(r)+J_{2}^{\prime}(r)\right),
$$

where

$$
\begin{aligned}
& J_{2}(r)=\int_{0}^{\pi} \frac{(1-r)^{2} \theta^{2 / r}}{\left\{(1-r)+\theta^{1 / \gamma}\right\}^{4}} d \theta, \\
& J_{2}^{\prime}(r)=\int_{0}^{\pi} \frac{(1-r)^{2} \theta^{2(\beta-1) / \beta r}}{\left(1-r+\theta^{1 / \gamma}\right)^{2}(1-r+\theta)^{2}} d \theta .
\end{aligned}
$$


Putting $\theta=t(1-r)^{r}$, we have

$$
J_{2}(r)<(1-r)^{r} \int_{0}^{\infty} \frac{t^{2 / r}}{\left(1+t^{1 / \gamma}\right)^{4}} d t
$$

the integral existing since $0<\gamma<1$. Let $L_{1}, L_{2}, L_{3}$ denote the contributions to the integral $J_{2}^{\prime}$ arising from the subintervals $[0,1-r]$, $\left[1-r,(1-r)^{r}\right]$ and $\left[(1-r)^{r}, \pi\right]$ respectively. Then

$$
\begin{aligned}
& L_{1}<\int_{0}^{1-r}(1-r)^{-2} \theta^{2(\beta-1) / \beta \gamma} d \theta<K(1-r)^{(2 \beta-2-\beta \gamma) / \beta \gamma}, \\
& L_{2}<\int_{1-r}^{(1-r) \gamma} \theta^{2(\beta-1-\beta \gamma) / \beta \gamma} d \theta<K\left((1-r)^{(2 \beta-2-\beta \gamma) / \beta}+(1-r)^{(2 \beta-2-\beta \gamma) / \beta r}\right), \\
& L_{3}<\int_{(1-r) \gamma}^{\pi}(1-r)^{2} \theta^{-2(\beta \gamma+1) \beta \gamma} d \theta<K(1-r)^{(2 \beta-2-\beta \gamma) / \beta},
\end{aligned}
$$

and therefore (3.20) gives

$$
I_{2}(r)<K\left((1-r)^{(2 \beta-2-\beta \gamma) / \beta \gamma}+(1-r)^{(2 \beta-2-\beta \gamma) / \beta}+(1-r)^{\gamma}\right) .
$$

In considering the integral $I_{3}(r)$ we use the inequality (3.13) to obtain immediately

$$
I_{3}(r)<\int_{0}^{\pi} \frac{K(1-r)^{2-2 / \beta}}{\left\{(1-r)^{\gamma}+\theta\right\}^{2}} d \theta<K(1-r)^{(2 \beta-2-\beta r) / \beta} .
$$

For a given value of $r$, we have $\pi_{4}\left(r e^{i \theta}\right)=1$ except possibly when

$$
\frac{1}{4}(1-r)^{1 / \beta} \leqq \theta^{1 / \beta \gamma} \leqq 4(1-r)^{1 / \beta} .
$$

Hence, by (3.16), we have immediately that

$$
I_{4}(r)<K(1-r)^{(2 \beta-2-\beta r) / \beta} .
$$

Finally, we note that the inequality (3.6) can be suitably adapted and applied to $\pi_{5}\left(r e^{i \theta}\right)$ so that, together with (3.17), we obtain

$$
\begin{aligned}
I_{5}(r) & <K(1-r)^{-1 / \beta} \sum_{n=N-1}^{N+2} \int_{0}^{\pi}\left(\log \left(1+\frac{4 \pi^{2}(1-r)\left(1-r_{n}\right)}{\theta^{2}}\right)^{2}\right) d \theta \\
& <K(1-r)^{-1 / \beta} \int_{0}^{\pi} \log \left(1+\frac{4 \pi^{2}(1-r)^{2}}{\theta^{2}}\right)^{2} d \theta \\
& <K(1-r)^{1-1 / \beta} .
\end{aligned}
$$

By applying the inequalities (3.19), (3.21), (3.22), (3.23), and (3.24) to (3.18) we obtain (3.4). If we now substitute $\beta=2 /(2-\gamma)$, we find that $B\left(z,\left\{z_{n}\right\}\right) \in \mathscr{J}$, and we have a sequence $\left\{z_{n}\right\}$ that satisfies the requirements of Theorem 2 . 


\section{Further properties of Blaschke products in $\mathscr{J}$.}

4.1. We are now in a position to comment on the implications of Theorem 1 and Theorem 2 concerning the distribution of the zeros of those Blaschke products that are in $\mathscr{F}$. First we have an extension of the result II of MacLane and Rubel which was stated in $\S 1$.

Corollary 1. Let $B\left(z,\left\{z_{n}\right\}\right) \in \mathscr{F}$, and let the sequence of points $\left\{z_{n}\right\}$ be contained in a finite number of Stolz angles with vertices on $\{z:|z|=1\}$. Then there is a constant $C$ such that

$$
N\left(r,\left\{z_{n}\right\}\right)<\frac{C}{(1-r)^{1 / 2}}, \quad 0<r<1 .
$$

The proof of this corollary is based on the fact that, for any given finite set of Stolz angles, the annulus $\left\{z: r<|z|<\frac{1}{2}(1+r)\right\}$ intersects those Stolz angles in a set that can be covered by a finite (fixed) number of sets of the form $A(r, \xi, 1-r)$ for $0<r<1$. However, by (1.9) of Theorem 1, there is a constant $H$ such that each of these sets contains fewer than $H(1-r)^{-1 / 2}$ elements of $\left\{z_{n}\right\}$. A simple summation argument then gives Corollary 1 as stated.

A further extension of this type can be obtained from the conclusion (1.10) of Theorem 1. Let

$$
T(\theta, \kappa, \gamma)=\bigcup_{0<r<1} A\left(r, \theta, \kappa(1-r)^{r}\right) .
$$

Sets of this sort have been considered elsewhere [1] in the theory of Blaschke products. If $\gamma=1$ then $T(\theta, \kappa, \gamma)$ is a close approximation, near the point $e^{i \theta}$, to a Stolz angle with vertex at $e^{i \theta}$. If $0<\gamma<1$ and $\kappa>0$ then the boundary of $T(\theta, \kappa, \gamma)$ meets $\{z:|z|=1\}$ only at $e^{i \theta}$, and this boundary has a common tangent with the circle there. The following corollary can be deduced from (1.10) in much the same way as Corollary 1 was deduced from (1.9).

Corollary 2. Let $B\left(z,\left\{z_{n}\right\}\right) \in \mathscr{J}$, let $0<\gamma<1$, and let $\kappa>0$. If the sequence $\left\{z_{n}\right\}$ is contained in a finite number of sets $T\left(\theta_{p}, \kappa, \gamma\right)$, $p=1,2,3, \cdots, P$, then there is a constant $C$ such that

$$
N\left(r,\left\{z_{n}\right\}\right)<C(1-r)^{-1+\gamma / 2}, \quad 0<r<1 .
$$

4.2. We now make a comparison of the conclusions of Theorem 1 that are embodied in the inequalities (1.9) and (1.10) respectively. Let $0<\gamma<1$ and $\kappa>0$. It is readily seen that the set

$$
A\left(r, \theta, \kappa(1-r)^{r}\right)
$$

contains $L(r)$ mutually disjoint sets of the form $A(r, \xi, 1-r)$, where 


$$
L(r) \sim \kappa(1-r)^{r-1} \text { as } r \rightarrow 1-0 .
$$

By (1.9) there is a constant $H$ such that each of these $L(r)$ sets contains fewer than $H(1-r)^{-1 / 2}$ points $\left\{z_{n}\right\}$, this result being of the best possible order of magnitude as $r \rightarrow 1-0$. Although some of the $L(r)$ disjoint sets $A(r, \xi, 1-r)$ may contain a comparatively large number of points $\left\{z_{n}\right\}$, not all of them can; in fact, for any constant $H_{0}$, there is a constant $H_{1}$ such that fewer than $H_{1}(1-r)^{(\gamma-1) / 2}$ of the $L(r)$ sets can contain more than $H_{0}(1-r)^{-1 / 2}$ points of $\left\{z_{n}\right\}$. In virtue of (4.1) rather few of the sets $A(r, \xi, 1-r)$ can contain more than $H_{0}(1-r)^{-1 / 2}$ points of $\left\{z_{n}\right\}$, and, since the remarks of this section hold for every $\gamma$ in $(0,1)$, those sets cannot be too close together in general.

4.3. MacLane and Rubel have verified the property III by constructing an appropriate Blaschke product $B\left(z,\left\{z_{n}\right\}\right)$ with the sequence $\left\{z_{n}\right\}$ distributed fairly uniformly near the boundary of $D(0,1)$, the whole boundary being the set of accumulation points of $\left\{z_{n}\right\}$. In proving Theorem 2 we have shown that for each number $\lambda$ in $(0,1)$ there is a Blaschke product $B\left(z,\left\{z_{n}\right\}\right)$ that belongs to $\mathscr{F}$, for which (1.7) is satisfied, and for which $\left\{z_{n}\right\}$ has only one accumulation point on $\{z:|z|=1\}$. Thus, in order that a Blaschke product $B\left(z,\left\{z_{n}\right\}\right)$ in $\mathscr{J}$ should have its counting function $N\left(r,\left\{z_{n}\right\}\right)$ large as $r \rightarrow 1-0$ it is not necessary for the Blaschke sequence $\left\{z_{n}\right\}$ to have more than one accumulation point on $\{z:|z|=1\}$. However, if $\left\{z_{n}\right\}$ has only one accumulation point $e^{i \theta}$ and $N\left(r,\left\{z_{n}\right\}\right)$ is large as $r \rightarrow 1-0$ then, by Corollary 2 , it is necessary that the points of the sequence $\left\{z_{n}\right\}$ should be widely dispersed in the neighbourhood of $e^{i \theta}$ in the sense that, for infinitely many $n,\left(\theta-\arg z_{n}\right)$ should be large in comparison with fixed positive powers of $1-\left|z_{n}\right|$.

4.4. Next we note that Theorem 1 implies a restriction on the orders of multiple zeros of Blaschke products in $\mathscr{F}$. For example, the application of (1.9) gives immediately the following corollary.

COROLlaRy 3. Let $B\left\{z,\left\{z_{n}\right\}\right)$ be a Blaschke product in $\mathscr{J}$, and let $\rho\left(z_{n}\right)$ denote the order of the zero of $B\left(z,\left\{z_{n}\right\}\right)$ at $z_{n}$. Then

$$
\rho\left(z_{n}\right)\left(1-\left|z_{n}\right|\right)^{1 / 2}=O(1) \text { as } n \rightarrow \infty \text {. }
$$

In comparison with (4.2) we note the weaker relation

$$
\rho\left(z_{n}\right)\left(1-\left|z_{n}\right|\right) \rightarrow 0 \text { as } n \rightarrow \infty
$$

which is valid, and in fact best possible, for the class of all Blaschke products $B\left(z,\left\{z_{n}\right\}\right)$. Incidentally, (4.3) shows that (1.10) is not best 
possible in the case where $\gamma=0$, although in general the index $1-\frac{1}{2} \gamma$ cannot be reduced to any smaller constant in this case.

4.5. Finally we comment on those Blaschke sequences $\left\{z_{n}\right\}$ for which $I\left(r,\left\{z_{n}\right\}\right)$ is small as $r \rightarrow 1-0$, noting the following immediate consequence of (3.3) and (3.4).

Corollary 4. Let $0<\gamma<1, \beta>2 /(2-\gamma)$. Then there is a Blaschke sequence $\left\{z_{n}\right\}$ such that

$$
I\left(r,\left\{z_{n}\right\}\right)=o(1)
$$

while

$$
\nu\left(r, 0,(1-r)^{\gamma}\left\{z_{n}\right\}\right) \sim\left(2^{1 / \beta}-1\right)(1-r)^{-1 / \beta}
$$

as $r \rightarrow 1-0$.

\section{REFERENCES}

1. G. T. Cargo, Angular and tangential limits of Blaschke products and their successive derivatives, Canadian J. Math., 14 (1962), 334-348.

2. C. N. Linden, The distribution of the zeros of regular functions, Proc. London Math. Soc., (3) 15 (1965), 301-322.

3. G. R. MacLane and L. A. Rubel, On the growth of Blaschke products, Canadian J. Math., 21 (1969), 595-601.

4. L. A. Rubel, A Fourier series method for entire functions, Duke Math. J., 30 (1963), 437-442.

Received August 6, 1970.

University College of SWansea

WALES 



\section{PACIFIC JOURNAL OF MATHEMATICS}

\section{EDITORS}

\author{
H. SAMELSON \\ Stanford University \\ Stanford, California 94305 \\ C. R. HовBY \\ University of Washington \\ Seattle, Washington 98105
}

J. DUGUndis

Department of Mathematics

University of Southern California

Los Angeles, California 90007

RICHARD ARENS

University of California

Los Angeles, California 90024

\section{ASSOCIATE EDITORS}
E. F. BeCKenbaCH
B. H. NeUmanN
F. WOLF
K. YoshidA

\section{SUPPORTING INSTITUTIONS}

\author{
UNIVERSITY OF BRITISH COLUMBIA \\ CALIFORNIA INSTITUTE OF TECHNOLOGY \\ UNIVERSITY OF CALIFORNIA \\ MONTANA STATE UNIVERSITY \\ UNIVERSITY OF NEVADA \\ NEW MEXICO STATE UNIVERSITY \\ OREGON STATE UNIVERSITY \\ UNIVERSITY OF OREGON \\ OSAKA UNIVERSITY \\ UNIVERSITY OF SOUTHERN CALIFORNIA
}

\author{
STANFORD UNIVERSITY \\ UNIVERSITY OF TOKYO \\ UNIVERSITY OF UTAH \\ WASHINGTON STATE UNIVERSITY \\ UNIVERSITY OF WASHINGTON

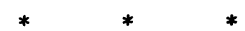 \\ AMERICAN MATHEMATICAL SOCIETY \\ CHEVRON RESEARCH CORPORATION \\ NAVAL WEAPONS CENTER
}

The Supporting Institutions listed above contribute to the cost of publication of this Journal, but they are not owners or publishers and have no responsibility for its content or policies.

Mathematical papers intended for publication in the Pacific Journal of Mathematics should be in typed form or offset-reproduced, (not dittoed), double spaced with large margins. Underline Greek letters in red, German in green, and script in blue. The first paragraph or two must be capable of being used separately as a synopsis of the entire paper. The editorial "we" must not be used in the synopsis, and items of the bibliography should not be cited there unless absolutely necessary, in which case they must be identified by author and Journal, rather than by item number. Manuscripts, in duplicate if possible, may be sent to any one of the four editors. Please classify according to the scheme of Math. Rev. Index to Vol. 39. All other communications to the editors should be addressed to the managing editor, Richard Arens, University of California, Los Angeles, California, 90024.

50 reprints are provided free for each article; additional copies may be obtained at cost in multiples of 50 .

The Pacific Journal of Mathematics is published monthly. Effective with Volume 16 the price per volume (3 numbers) is $\$ 8.00$; single issues, $\$ 3.00$. Special price for current issues to individual faculty members of supporting institutions and to individual members of the American Mathematical Society: $\$ 4.00$ per volume; single issues $\$ 1.50$. Back numbers are available.

Subscriptions, orders for back numbers, and changes of address should be sent to Pacific Journal of Mathematics, 103 Highland Boulevard, Berkeley, California, 94708.

PUBLISHED BY PACIFIC JOURNAL OF MATHEMATICS, A NON-PROFIT CORPORATION

Printed at Kokusai Bunken Insatsusha (International Academic Printing Co., Ltd.), 7-17, Fujimi 2-chome, Chiyoda-ku, Tokyo, Japan. 


\section{Pacific Journal of Mathematics}

Vol. 38, No. $2 \quad$ April, 1971

Richard Davis Anderson and Thomas Ashland Chapman, Extending

homeomorphisms to Hilbert cube manifolds .................. 281

Nguyen Huu Anh, Restriction of the principal series of $\operatorname{SL}(n, \mathbf{C})$ to some

reductive subgroups................................ 295

David W. Boyd, Indices for the Orlicz spaces . . . . . . . . . . . . 315

William Garfield Bridges, The polynomial of a non-regular digraph ...... 325

Billie Chandler Carlson, Robert K. Meany and Stuart Alan Nelson, Mixed

arithmetic and geometric means........................ 343

H. A. Çelik, Commutative associative rings and anti-flexible rings ...... 351

Hsin Chu, On the structure of almost periodic transformation groups ...... 359

David Allyn Drake, The translation groups of n-uniform translation

Hjelmslev planes ................................ 365

Michael Benton Freeman, The polynomial hull of a thin two-manifold . . . . 377

Anthony Alfred Gioia and Donald Goldsmith, Convolutions of arithmetic

functions over cohesive basic sequences .................... 391

Leslie C. Glaser, A proof of the most general polyhedral Schoenflies

conjecture possible ................................

Thomas Lee Hayden and Ted Joe Suffridge, Biholomorphic maps in Hilbert

space have a fixed point ................................ 419

Roger Alan Horn, Schlicht mappings and infinitely divisible kernels ...... 423

Norman Ray Howes, On completeness ...................... 431

Hideo Imai, Sario potentials on Riemannian spaces................ 441

A. A. Iskander, Subalgebra systems of powers of partial universal

algebras.

Barry E. Johnson, Norms of derivations of $\mathscr{L}(\mathrm{X})$.

David Clifford Kay and Eugene W. Womble, Axiomatic convexity theory and relationships between the Carathéodory, Helly, and Radon numbers

Constantine G. Lascarides, A study of certain sequence spaces of Maddox

and a generalization of a theorem of Iyer .............

C. N. Linden, On Blaschke products of restricted growth .

John S. Lowndes, Some triple integral equations ................. 515

Declan McCartan, Bicontinuous preordered topological spaces ......... 523

S. Moedomo and J. Jerry Uhl, Jr., Radon-Nikodým theorems for the Bochner and Pettis integrals ...

Calvin Cooper Moore and Joseph Albert Wolf, Totally real representations

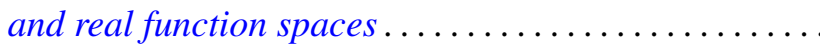

Reese Trego Prosser, A form of the moment problem for Lie groups. ... 